\title{
La violencia institucional como violencia de género: El espectáculo mediático y el caso irlandés
}

\author{
Institutional violence as gender violence: \\ The media spectacle and the Irish case
}

\author{
José María Maitini ${ }^{1}$ \\ Universidad Nacional de La Plata - Argentina \\ Jéssica Belén Gizzi² \\ Universidad Siglo XXI - Argentina
}

Revista Derechos en Acción ISSN 2525-1678/ e-ISSN 2525-1686

Año 5/No 16 Invierno 2020 (21 junio a 20 septiembre), 681-689

DOI: https://doi.org/10.24215/25251678e438

Recibido: 01/07/2020

Aprobado: 15/09/2020

\section{Violencia institucional: marco teórico}

La violencia de género también se manifiesta como violencia institucional dentro del entramado estatal. Este tipo de violencia es contemplado en nuestro plexo normativo de leyes y convenciones. La Ley de Protección Integral a las mujeres (2019) contempla en su art. 4: "Se entiende violencia contra la

\footnotetext{
1 Profesor en Letras y Abogado por la Universidad Nacional de La Plata. Asesor Legal Instituciones Educativas del Alto Valle y desempeño en la actividad privada penal. Corrector de Revista de Derechos en Acción de la Facultad de Ciencias Jurídicas y Sociales de la Universidad de La Plata. Email: josemaitini@hotmail.com (ORCID: https://orcid.org/00000003-0866-682X).

2 Abogada. Integrante del Ministerio Público Fiscal de la Provincia de Rio Negro, Jefe de Despacho de Fiscales, Fiscalía Descentralizada de la Ciudad de Cinco Saltos, Río Negro. Email: jessicaa.09@hotmail.com (ORCID: https://orcid.org/0000-0002-3542-9494)).
} 
mujer como toda conducta, acción u omisión, que de manera directa o indirecta, tanto en el ámbito público como en el privado, basada en una relación desigual de poder, afecte su vida, libertad, dignidad, integridad física, psicológica, sexual, económica o patrimonial, como así también su seguridad personal. Quedan comprendidas las perpetradas desde el Estado o por sus agentes [el resaltado es nuestro]. La Declaración sobre la eliminación de la violencia contra la mujer también profundiza el concepto en su art. 2: "una de las formas de violencia física, sexual o psicológica es aquella perpetrada o tolerada por el Estado, donde quiera que ocurra" (Asamblea General Naciones Unidas, 1993).

La Convención de Belem do Para (1994), por otro lado, incluye en su art. 2, inc. "c" la violencia "ejercida por el Estado o sus agentes donde quiera que ocurra". Y aclara especialmente en su capítulo III, art. 7, inc. "a" como deber del Estado: "abstenerse de cualquier acción o práctica contra la mujer y velar porque las autoridades, sus funcionarios, personal, instituciones se comporten de conformidad con esta obligación" (Organización de los Estado Americanos, 1996). A nivel nacional, la Ley de Protección Integral a las Mujeres establece en su art. 2 "prevenir, sancionar y erradicar la discriminación y la violencia contra las mujeres en cualquiera de sus manifestaciones y ámbitos" (Congreso de la Nación, 2009)

En torno a la jurisprudencia internacional en torno a la temática, creemos importante resaltar dos hitos donde la Comisión Interamericana de Derechos Humanos aplicó Convención de Belem do Para. En la primera, en el caso Maria Da Penha contra Brasil, afirmaron que "la violencia forma parte de un patrón general de negligencia y falta de efectividad del Estado" (CIDH, 2001) luego de que la víctima denunciara constantemente violencia doméstica de parte de su marido. En un segundo caso, Gonzalez y otros contra México, anunciaron que "el Estado no dispuso los medios adecuados para luchar contra los estereotipos de género y éste sería una de las causas y consecuencias de la violencia". Y agregaron también: "el 
Estado es cómplice [el resaltado es nuestro] muchas veces con el crimen cuando en realidad debe ser el garante primero de la igualdad" (CIDH, 2009). La Corte Interamericana condenó como responsable al Estado Mexicano por las faltas de diligencias en las investigaciones del asesinato de tres mujeres, sus cuerpos encontrados en un campo algodonero de la ciudad de Juárez un 06 de Noviembre de 2001.

El marco teórico nacional e internacional, como se puede observar, es muy preciso en cuanto a la responsabilidad estatal cuando de cuestiones de género hablamos. Sin embargo, a pesar de estos fallos orientadores, guías, estos leitmotivs jurisprudenciales y normativos, los casos de violencia institucional como violencia de género se siguen perpetrando. Veamos.

\section{Problemática puntual de R.P. en Cipolletti, Rio Negro}

Establecido el marco teórico, pasemos al hecho puntual. Escribimos desde la ciudad de Cipolletti, Provincia de Rio Negro. A fines del año 2019 en esta ciudad se llevó adelante una primera parte del juicio al ginecólogo Lastra por no cumplir con sus deberes como profesional (art. 248, Capítulo IV Código Penal). No estaba inscripto en la lista de "Objetores de Conciencia" y se negó a interrumpir un embarazo producto de una violación previa declaración jurada de la víctima.

R.P. sufrió violencia médica al ser negada en su derecho a abortar; violencia obstétrica por haber sido medicada sin darle explicaciones ni argumentos; y violencia institucional porque el Estado, arropado de cómplice y revictimizándola, le negó sistemáticamente - en dos hospitales públicos distintos- el derecho a practicar aborto cuando la misma víctima había insistido - una y otra vez- que fue ultrajada en su integridad sexual.

Todos lo sabemos: el aborto no es punible frente a violación. No sólo porque lo permite el código penal (art. 86 inc.2) sino también por lo ya establecido en el más que conocido caso $F A L$ (2012). Se suma a eso también el "Protocolo para la Atención 
integral de las personas con derecho a la interrupción legal del embarazo" del Ministerio de Salud del año 2015 y, en el caso de nuestra provincia, la Ley Ley No 4796, Ley de Atención Sanitaria en casos de Abortos no punibles. Y también otra cosa tenemos clara también: un médico puede ser objetor de conciencia, pero la institución en sí misma tiene el deber de garantizarlo.

El ginecólogo fue condenado penalmente por no practicar aborto cuando hubo violación. R.P. afirmó ser violada, quería abortar y, a pesar de todo, no pudo porque Lastra se lo negó. Y para no practicar el aborto se apeló a los argumentos más insólitos: no se hizo porque se buscó "preservar su salud", porque "no sabía que había sido violada" y porque "la violación no se había constatado". Y peor aún: el ginecólogo le exigió un informe psiquiátrico por todos sus dichos. Albert Camus tenía una frase muy atinada en cuestiones como esta: "la necesidad de tener razón: señal de espíritu vulgar".

Diarios, televisión, radio, marchas, opiniones en bares patagónicos... todos se hicieron eco del caso y cada ciudadano ofrecía su punto de vista inducido por los medios que "orientaban" posturas para uno u otro lado de esta grieta de Género. Los medios buscaron atraer espectadores, ofreciendo un espectáculo del ultraje, como suele suceder en el caso de la violencia contra la mujer. Mejor aclarado en palabras de Rita Segato:

Se glamoriza en el sentido de que se transforma en un espectáculo. Se repite el hecho, se lo analiza, se busca detalles, sin ningún cuidado para el mimetismo que producen en la gente. Los medios están con una deuda con la sociedad (...) Y no hay voluntad mediática por ver cómo se va a tratar la cuestión de la ofensa sexual y al ofensa letal contra las mujeres (...) Debería haber un debate entre editores, profesores de comunicación, dueños de periódicos, dueños de canales de televisión, psicólogos sociales. Un debate mucho mayor sobre cómo se muestran estos fenómenos a la sociedad, de manera de informar sin promover, sin contagiar (Rita Segato, 2019). 
En el caso de R.P no existió posibilidad de que no se promueva, de que no se contagie, una postura que no la revictimizara cada vez que los medios aludían a ella. El psicólogo de R.P. llegó a pedir un "bozal legal" al propio ginecólogo. Pero a R.P. no le practicaron aborto sino todo lo contrario: le hicieron tener al hijo, lo dieron en adopción y existió grupos que celebraron ( aquí, por estas zonas de la Argentina) que se había preservado la vida de una persona nacida como producto de una violación. Como afirma Shakespeare (2012) en el Mercader de Venecia: "Muchas veces el mismo demonio, para disculpar sus maldades, cita las sagradas escrituras a su favor si vienen bien a sus propósitos".

Lo que ha sucedido en Cipolletti, Provincia de Río Negro, nos sirve para construir crítica acerca de lo obvio, lo elemental, que muchas veces se olvida: ante violación el aborto no es punible. ¿Y si no hay violación, puede abortar? Esto es lo que se debatió durante todo el 2019 en el Congreso y esperemos que este 2020 se vuelve a debatir. ¿Y si no hubo violación pero miente e igual quiere abortar? Esto ya se pensó en el caso FAL: el riesgo a que alguien mienta no puede ser nunca razón suficiente para imponer a las víctimas de delitos sexuales obstáculos que vulneren el goce efectivo del legítimo derecho. "Pero entonces... ¿miente sin ningún tipo de pudor y aborta?” preguntará algún lector desprevenido. Previa declaración jurada, sí. Por supuesto. Puede resultar escandaloso, pero debemos comprender que abortar no es ir a comprar golosinas al kiosco.

Quizá algún desprevenido se atreva a preguntar, en un ámbito de confianza, en un ámbito de amistades o familiar: "Pero... ¿Por qué tardó tanto en denunciar la violación? ¿Por qué tardó 5 meses como efectivamente pasó? Y esa pregunta quizá la contestamos con otra: ¿con qué falta de comprensión y de humanidad uno se anima a preguntar eso, indicando cómo reaccionar, como responder, a quién acudir y cómo, ante el dolor ajeno?

El debate sobre interrupción voluntaria del embarazo, la temática, nos presenta, a priori, dos males: interrumpir la vida o 
una maternidad forzada. En Cipolletti, en este hecho puntual a fines del año pasado, gran parte el sector cristiano defendió la vida (inclusive si esa vida fue producto de una violación. Sí: el sector cristiano pareció olvidarlo); por otro lado, el sector laico se proclamó en contra de la maternidad forzada.

Lo que primero que nos preguntamos es: ¿se escuchó a la mujer? ¿se escuchó a R.P.? Siempre hay que escuchar a la mujer y sus razones y aquí no se hizo. Todo lo contrario: la mandaron a realizarse un informe psiquiátrico. Como afirmó Diana Maffía en el debate sobre el Aborto en el Congreso:

Las mujeres somos capaces de gestar, de parir, de amamantar, pero esa capacidad no puede transformarse en una obligación. Tenemos el derecho a una maternidad deseada y no el deber de una maternidad forzada. Un embarazo deseado coincide con la voluntad procreacional, y el Estado está obligado a garantizar el respeto a ese proyecto vital. Un embarazo forzado es cuando no hay voluntad procreacional, o cuando hay obstáculos que nos dañan, y se evalúa entonces su continuidad o interrupción; y la persona gestante es quien debe decidirlo y debería tener derecho a interrumpirlo respaldada por el Estado (Maffia, Diana, 2018).

La pregunta que también nos hacemos, entonces, es la siguiente: ¿cómo preservar la vida sin obligar a continuar el embarazo? ¿Es justo obligar a soportar algo no deseado?

El derecho comparado nos esclarece la problemática. De 28 países que componen la Unión Europea, 22 permiten la interrupción voluntaria sin restricciones en cuanto a la razón, aunque con diferentes plazos de gestación (Olivia Sohr y Martinez Lucia, 2018). Gran Bretaña, por poner un solo ejemplo, permite el aborto por causales económicas. Sí: no tener plata es razón suficiente para acceder al aborto. Y, paradojalmente, son los países que tienen la interrupción voluntaria del embarazo los que menos abortos tienen.

Estamos convencidos que la única solución al dilema del aborto la tiene la propia mujer, dueña de su cuerpo y vida. 
Y también nos planteamos: ¿es posible que se reconozca una vida (al embrión) pero que se rechace otra (la mujer)? Sin querer entran en debate en cuanto al número, pero sabemos que muchas mueren por prohibirse la práctica. Y también entonces allí, en ese silencio poco inocente social, estamos rechazando vida. Como afirma Bauger (2019) en "Perspectiva de género y feminismos jurídicos en la enseñanza del derecho": puede hablarse de una auténtica ausencia de habeas corpus para las mujeres mientras no se les reconozca plena responsabilidad en orden a la procreación (p. 308).

El debate religioso-laico acerca de la interrupción voluntaria del embarazo tiene una esperanza, creemos, con el caso del país de Irlanda. Si Irlanda fuesen diez personas, ocho son católicos. Si Irlanda fuesen diez personas, en 2018 casi siete se proclamaron a favor del aborto hasta las doce primeras semanas sin motivo, previa visita médica. ¿Es un problema, entonces, el ser católico? ¿es un problema, entonces, la religiosidad en términos amplios? Quizá en algunos casos sí, puede ser un obstáculo. Pero en el caso de Irlanda no lo fue. Al menos no es problema para los irlandeses: Dios y el Aborto no parecen incompatibles para ellos. Pero el caso de nuestra región - el caso de R.P. — ni siquiera remite a voluntad sin daño: remite a violación. ¿Por qué tanto se generó tanto debate entonces? ¿Por qué se generó tanto revuelo? ¿No será acaso, como afirma Segato, que se glamoriza tanto la violencia, se construye tanto su espectáculo, que nos impide como sociedad el pensamiento crítico? Debemos entender que el problema del aborto es un problema de salud pública y también es un problema reconocimiento de tortura. Tortura también es que una mujer no pueda decidir sobre su propio cuerpo.

\section{Reflexiones Finales}

Debemos educar, prevenir, no criminalizar y respetar. Educar y prevenir para llegar antes. No criminalizar porque haciéndolo se consigue sólo muerte o tortura. Y, necesitamos también 
el respeto de todos los actores sociales, el respeto por el que piensa diferente. Respetándonos construimos comunidad, que es lo que nos falta para aceptar sufrir este debate. La unidad en este tema creemos que no es uniformidad. Sino que es unidad en lo diverso. En este caso como hacen los irlandeses: creer en Dios y en la interrupción voluntaria. Al mismo tiempo. En un mismo conflicto. Irlanda tiene algo de la clave: la unidad en lo diverso. Allí sí se asumió el conflicto.

Y debemos admitir que la mujer - y ningún Dios- es la única legitimada para decidir sobre su cuerpo. Con un Estado que lo garantice. Con mecanismos institucionales que estiren el manto protector garantizador de estas políticas. Y educando y respetando: única dos maneras luchar contra la violencia en todas sus manifestaciones y por una efectiva igualdad de derechos.

Y también debemos dejarlo claro: nadie está a favor de la muerte. Por eso creemos que es engañoso el lema "salvemos las dos vidas". Se suele decir que la única verdad es la realidad y ésta realidad que tenemos demuestra que el Código Penal no previene el aborto ni reduce los que se practican: sólo produce que las más pobres sean sometidas a los riesgos más altos.

Y como ha dicho Fabián Savioli en el Plenario de Comisiones acerca de la legalización del aborto: "justamente porque somos más "pro vida" que nadie creemos en la interrupción voluntaria del embarazo"

\section{Bibliografía}

Bauger, Erika Silvina (2019). "Perspectiva de género y feminismos jurídicos en la enseñanza del derecho" en Revista Derechos en Acción, $\mathrm{N}^{\circ} 11$ Otoño, Año 4, Universidad Nacional de La Plata, Argentina. En línea en: https://revistas.unlp.edu.ar/ReDeA/ article/view/7540/6718

Savioli, Fabián (2018). "Exposición de Fabián Savioli”. En Campaña Nacional para el Aborto Legal. Martes 22 de Junio de 2018. En línea en: https://www.youtube.com/watch?v=MlfBhle3tws 
Comisión Interamericana de Derechos Humanos (2001). "Maria da Pehna”. Informe $\mathrm{N}^{\circ}$ 54/01. En línea en: https://www.cidh.oas. org/annualrep/2000sp/CapituloIII/Fondo/Brasil12.051.htm

Congreso de la Nación (2009). Ley Nacional de Protección Integral a las Mujeres (Ley 26.485). En línea en: http://servicios.infoleg.gob.ar/infolegInternet/anexos/150000-154999/152155/ norma.htm

- (1984). Código Penal. Ley 11.179. En línea en: http://servicios. infoleg.gob.ar/infolegInternet/anexos/15000-19999/16546/ texact.htm

Organización de los Estados Americanos (1994). Convención Interamericana para Prevenir, Sancionar y Erradicar la Violencia contra la Mujer. Departamento de Derecho Internacional. En línea en: https://www.oas.org/juridico/spanish/tratados/a-61.html

Corte Interamericana de Derechos Humanos (2009). González y otras ("Campo Algodonero") Vs. México. Inter- American Court of Human Rights. En línea en: http://www.corteidh.or.cr/cf/ Jurisprudencia2/ficha_tecnica.cfm?nId_Ficha=347\&lang=es

Maffia, Diana (2018). "Para aportar al debate sobre el Aborto", 01 Junio 2018. Comisión Cámara de Diputados del Congreso de la Nación. En línea en: http://dianamaffia.com.ar/?p=12334

Naciones Unidas Derechos Humanos (1993). Declaración sobre la eliminación de la violencia contra la mujer. En línea en: https://www.ohchr.org/sp/professionalinterest/pages/violenceagainstwomen.aspx

Olivia Sohr y Martinez Lucia (2018). "Debate Aborto: chequeos a los argumentos a favor y en contra (II)". en Chequeado. En linea en: https://chequeado.com/ultimas-noticias/debateaborto-chequeos-a-los-argumentos-a-favor-y-en-contra-ii/

Shakespeare, William (2012). El Mercader de Venecia. Edición Libro de Bolsillo. $01^{\circ}$ Edición. Editorial Alianza. Madrid.

Segato, Rita. (2019): "Los femicidios se repiten porque se muestran como espectáculos". Entrevista exclusiva en Diario La Mañana del Neuquén. En línea en: https://www.lmneuquen. $\mathrm{com} /$ rita-segato-los-femicidios-se-repiten-porque-se-muestrancomo-un-espectaculo-n649114 